\title{
Changes in the cellular behaviour of human colonic cell line Caco-2 in response to butyrate treatment ${ }^{\star}$
}

\author{
Zofia Dzierżewicz ${ }^{\bowtie}$, Arkadiusz Orchel, Ludmiła Węglarz, Małgorzata Latocha \\ and Tadeusz Wilczok
}

\section{Department of Molecular Biology, Biochemistry and Biopharmacy, Silesian Medical University of Silesia, Sosnowiec, Poland}

Received: 10 September, revised: 21 December, 2001; accepted: 7 February, 2002

Key words: sodium butyrate, colonocytes, Caco-2 cells, differentiation, apoptosis, interleukin-8

\begin{abstract}
Gut-derived adenocarcinoma Caco-2 cells were treated with sodium butyrate (NaB) at physiologically relevant concentrations. We characterized its effects on proliferation, differentiation, apoptosis, adhesion to the solid support and interleukin-8 secretion. Differentiation was determined by brush border alkaline phosphatase activity. Apoptosis was assessed by acridine orange and Hoechst stains. Differentiation and apoptosis were analyzed in both adherent and floating cell populations. The transformed Caco-2 cells did not retain their malignant phenotype in the presence of $\mathrm{NaB}$. They appeared to undergo a change in the phenotype induced by $\mathrm{NaB}$, as indicated by reduced proliferation, enhanced differentiation, stimulation of apoptosis leading to decreased viability of cells, and stimulation of interleukin-8 secretion. Considering all the above facts and data, we postulate that Caco-2 cells cultured in $\mathrm{NaB}$ supplemented medium could regain the phenotypic characteristics of the phenotype of the parent cell from which originated the Caco-2 line.
\end{abstract}

Butyric acid is a short-chain fatty acid that is present in physiologically normal human large gut and is derived from anaerobic bacterial fermentation of luminal complex carbohydrates [1]. Butyrate is not only the preferred energy source for the colonic epithelium but also exhibits several other physiological and biological activities [2]. The cellular effects of butyrate are complex, especially since those observed in a cell system of normal phenotype

\footnotetext{
${ }^{\star}$ Presented at the 8th International Symposium on Molecular Aspects of Chemotherapy, September, 2001, Gdańsk, Poland.

${ }^{\otimes}$ Correspondence should be addressed to: Zofia Dzierżewicz, Department of Molecular Biology, Biochemistry and Biopharmacy, Silesian Medical University, Narcyzów 1, 41-200 Sosnowiec, Poland; tel: (48 32) 291 0088, e-mail: zofiadz@slam.katowice.pl
}

Abbreviations: ALP, alkaline phosphatase; NaB, sodium butyrate; IL-8, interleukin-8; FBS, fetal bovine serum; PBS, phosphate-buffered saline. 
may be the opposite of those in a transformed cell system. This so-called "butyrate paradox" has been observed in relation to cell proliferation, differentiation and apoptosis [3-5]. Butyrate was shown to be a trophic factor for normal colonic epithelial cells both in vivo and in vitro [6]. Epithelial cell proliferation was also stimulated in atrophic colonic epithelium in the presence of butyrate [7]. Butyrate inhibits apoptosis in intact colonic mucosa cultured in vitro [8]. In contrast, in tumour cells and colorectal cell lines butyrate inhibits proliferation and promotes differentiation [9-11]. In vivo, luminal butyrate concentrations are inversely correlated with tumour size in experimental colorectal tumorigenesis [12], and direct colonic instillation of butyrate reduced the size and number of tumours in experimental carcinogenesis [13, 14]. Rectal enemas of butyrate as a therapeutic approach seem to be a promising option also in adenomatous polyps and some forms of inflammatory bowel disease [15].

Considerable experimental efforts are currently expanded in order to define the effects and mechanisms of butyrate action at the cellular level. Since it was reported that butyrate might decrease adhesiveness of Caco-2 cells to substrate [9], we hypothesized that butyrate could induce cell apoptosis by the disturbance of cell interaction with the substrate. To verify this hypothesis, we compared apoptosis induction by sodium butyrate $(\mathrm{NaB})$ in cells cultured on standard plastic substrate and on laminin substrate that strongly facilitates cell adhesion. Also, we performed a quantitative analysis of cell apoptosis in the presence of $\mathrm{NaB}$ in terms of attached and floating cells apoptosis examination in the cell culture, the analysis which previously has not been reported with the cell line of our interest. Moreover, the behaviour of cells plated on adhesive substrate and then treated with $\mathrm{NaB}$ was compared with that of cells seeded with no $\mathrm{NaB}$ on the plate covered with polyHEMA. Proliferation dynamics, differentiation of cells and interleukin-8 secretion in cells cultured with $\mathrm{NaB}$ were additionally studied.

\section{MATERIALS AND METHODS}

A human colon adenocarcinoma cell line Caco-2 was purchased from German Collection of Microorganisms and Cell Cultures and cultured according to producer's instructions. The cells were maintained at $37^{\circ} \mathrm{C}$ in $5 \% \mathrm{CO}_{2}$ in RPMI 1640 medium supplemented with $10 \%$ fetal bovine serum (FBS), $2 \mathrm{mM}$ glutamine, $100 \mathrm{U} / \mathrm{ml}$ penicillin and $100 \mu \mathrm{g} / \mathrm{ml}$ streptomycin. Sodium butyrate was purchased from Sigma and in different sets of experiments used at a range of concentrations of $2.5-20 \mathrm{mM}$.

Cell proliferation was quantitated by serial cell counts. Cells were plated on plastic 21.5 $\mathrm{cm}^{2}$ dishes $\left(2.5 \times 10^{5}\right.$ cells $/$ dish $)$ in normal medium and allowed to grow for 3 days before being exposed to NaB-supplemented medium for up to 6 days. Cell growth was assessed by counting the adherent cells in a hematocytometer. In another set of experiments cells were plated in $\mathrm{NaB}$ containing medium and adherent cell number was estimated after 5 days of culture.

As a measure of cell differentiation, alkaline phosphatase (ALP) activity was determined in cell lysates by a commercially available kit. Sub-confluent Caco-2 cells were grown in NaB-supplemented medium (5 mM and 10 $\mathrm{mM}$ ) for 2 and 4 days. Culture supernatants were harvested and nonadherent cells were removed by centrifugation and then used for ALP assay. Adherent cells were harvested in cold Tris-buffered saline solution (pH 7.4) and also used for ALP assay. Results were expressed relative to cellular protein content which was determined spectrophotometrically by the Bradford's method with bovine albumin as a standard.

In order to measure interleukin- 8 secretion, Caco-2 cells were seeded in a 12 -well plate 
$\left(2 \times 10^{5}\right.$ cells/well) and cultured to confluence in FBS containing medium. After confluence was reached, the culture medium was changed from that containing serum to that without serum and cells were cultured for the next three days. Then cells were treated with 5 $\mathrm{mM} \mathrm{NaB}$ for $24 \mathrm{~h}$ followed by replacement of the medium with a fresh one containing $5 \mathrm{mM}$ $\mathrm{NaB}$, for other $24 \mathrm{~h}$. IL-8 concentration was measured in the medium collected after 24 and $48 \mathrm{~h}$ incubation with $\mathrm{NaB}$ by a commercially available ELISA kit (R\&D).

To characterize the effect of butyrate on Caco-2 cells apoptosis, cells were allowed to grow in normal medium for 3 days before being exposed to $2.5 \mathrm{mM}, 5 \mathrm{mM}$ or $10 \mathrm{mM} \mathrm{NaB}$ for 2 and 5 days. Then cells which became detached and floated in the medium were collected, counted and analyzed for apoptosis. Attached cells were resuspended into a single cell suspension by light trypsinization, then counted and also analyzed for apoptosis. The level of apoptosis in the cultured cell line was assessed by measuring the proportion of the total cell population that had detached from the cell monolayers and was floating in the medium, and determining the fraction of these floating cells that were apoptotic. Also, the fraction of adherent cells that were apoptotic was determined in relation to the total cell population that remained adherent to the tissue culture flasks. Apoptosis was characterized morphologically by acridine orange ( $5 \mu \mathrm{g} / \mathrm{ml}$ in phosphate-buffered saline, PBS) or Hoechst $33342(1 \mu \mathrm{g} / \mathrm{ml}$ in PBS) staining which visualizes the condensed chromatin and fragmented nuclei of apoptotic cells. Cells stained with the dyes were viewed by fluorescence microscopy (Olympus BX-60), as described by Hague et al. [16] and Singh et al. [17]. In both fractions (attached and detached) the total number of cells and that of apoptotic cells were counted in 20 random fields per preparation.

For assessment of the effect of substrate type on the Caco-2 cells susceptibility to undergo apoptosis in the presence of $\mathrm{NaB}$, cells were plated on plastic dishes coated with laminin and 3 days later were treated with a NaB-supplemented medium (2.5 mM, $5 \mathrm{mM}$ and $10 \mathrm{mM}$ ) for 2 and 5 days. Afterwards, the attached and floating cells were counted separately, then stained with acridine orange or Hoechst 33342 for examination by fluorescence microscopy.

A separate experiment was intended to visualize how the Caco-2 cells would behave when plated on a plastic dish precoated with polyHEMA (poly(2-hydroxyethylmetacrylate), Sigma) which is known to prevent cell adhesion to the tissue culture flask. PolyHEMA was prepared in $95 \%$ ethanol to give the final concentration of $10 \mathrm{mg} / \mathrm{ml}$. Culture dishes were coated with $0.1 \mathrm{ml}$ of the solution per $\mathrm{cm}^{2}$ of surface. Cells were treated with butyrate-free fully supplemented medium for up to 4 days. Nonadherent cells were collected at one day intervals, fixed, stained with Hoechst 33342 and examined by microscopy for apoptosis. Cells were also stained with trypan blue for necrosis.

\section{RESULTS}

The presence of $\mathrm{NaB}$ in Caco-2 cell cultures caused inhibition of cell proliferation (Fig. 1). The results indicated that growth inhibition was dependent on both $\mathrm{NaB}$ concentration and time of incubation. They suggest the occurrence of interaction of these factors in growth inhibition of Caco- 2 cells. To verify the above supposition, the data were analyzed by two-way ANOVA. The analysis confirmed the existence of postulated interaction $(P<$ 0.0001), except for the difference in dynamics of cell number changes with the increase of $\mathrm{NaB}$ concentration from $10 \mathrm{mM}$ to $20 \mathrm{mM}$ $(P=0.0609)$. When $\mathrm{NaB}$ was present in the culture medium at the moment of cell plating, the attached cell yield on the 5th day of incubation was markedly reduced compared with the inhibition of proliferation by $\mathrm{NaB}$ added to the culture on the 3rd day after plating 


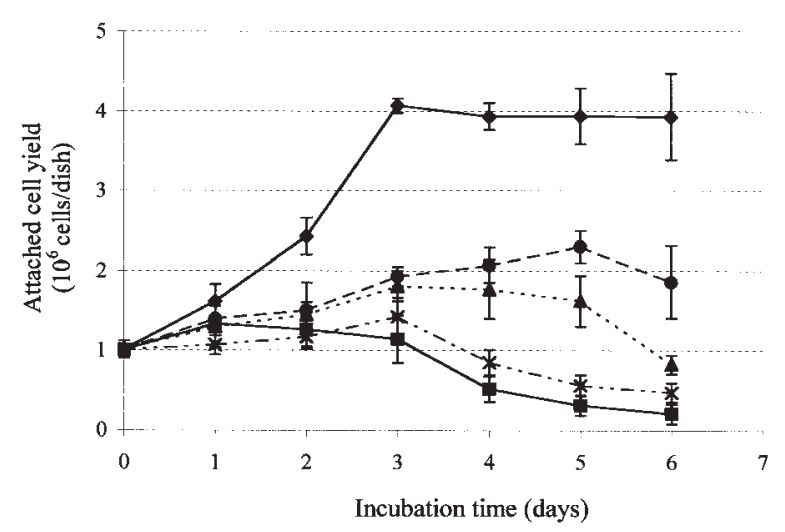

Figure 1. Growth curves of Caco-2 cells cultured in the presence of $\mathrm{NaB}$, estimated by counting using a hematocytometer.

Cells were cultured without $(\diamond)$ or with increasing concentrations of $\mathrm{NaB}$. The concentrations used were: 2.5 $\mathrm{mM}(\mathbf{O}), 5 \mathrm{mM}(\boldsymbol{\Delta}), 10 \mathrm{mM}(\times)$ and $20 \mathrm{mM}(\boldsymbol{\square}) . \mathrm{NaB}$ was added to the medium 3 days after plating. Each curve is the mean \pm S.D. of 3 different experiments.

(Fig. 2). This indicates that $\mathrm{NaB}$ present in the medium at the culture start prevented cells from leaving lag phase and entering exponential growth. Figure 3 displays the NaB dose dependent reduction of cell density, reduction of area occupied by cells and increase in floating cells yield after 5 days of $\mathrm{NaB}$ treatment.

To determine whether the Caco- 2 cells underwent differentiation in the presence of $\mathrm{NaB}$, we estimated the ALP activity, both in attached and floating cell populations. Treatment of Caco- 2 cells with $\mathrm{NaB}$ resulted in changes in ALP activity compared to untreated cells used as control (Fig. 4). The observed changes of enzyme activity depended on both $\mathrm{NaB}$ concentration and time of incubation. Interaction of these factors was confirmed by results of statistical analysis of data (two-way ANOVA) for both attached $(P=0.0417)$ and floating $(P=0.013)$ cells. Since it has been suggested that the process of apoptosis and differentiation might be occurring simultaneously in vivo, and the floating cells in the NaB-treated cultures were predominantly apoptotic (see below), we aimed at determination whether the Caco- 2 cells undergoing apoptosis were differentiated. For this purpose, we analyzed the ALP activity also in

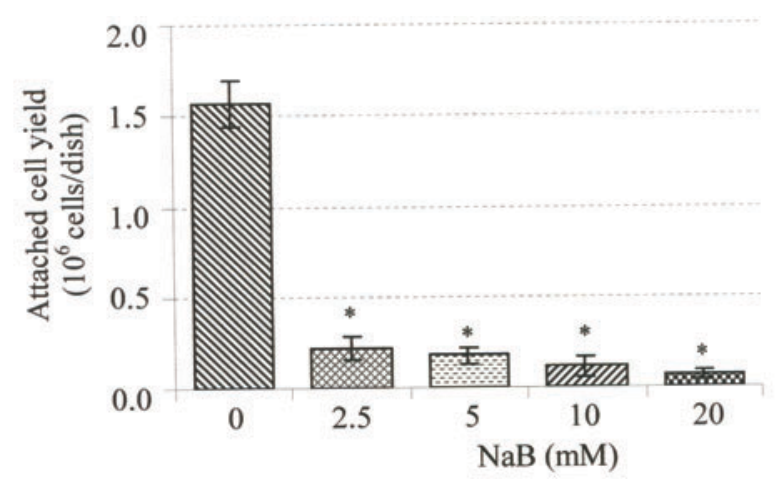

Figure 2. Effect of $\mathrm{NaB}$ added to culture medium simultaneously with the plating, on cell proliferation.

Cells were counted using a hematocytometer 5 days after plating. Each bar represents the mean \pm S.D. of four independent experiments. ${ }^{*} P<0.05$.

NaB-treated cells floating in the culture medium (Fig. 4B). Floating cells showed greater ALP activity after 4 days treatment with $\mathrm{NaB}$ than untreated cells (282\% and $402 \%$ increase at $5 \mathrm{mM}$ and $10 \mathrm{mM}$ concentration respectively, $P<0.0001$ ). On the other hand, NaB-treated adherent cells exhibited 10-fold higher ALP activity compared with NaB-treated floating cells after 4 days of culture. Within 2 days treatment with $\mathrm{NaB}$ the floating cells did not express a differentiated phenotype. Based on our results it cannot be suggested that the two processes are interdependent. Anyway, to define the role of apoptosis in enterocyte terminal differentiation a different mode of study is required in order to separate the two events.

The Caco-2 cells secreted greatly increased amounts of IL- 8 in response to $\mathrm{NaB}$ treatment compared to control $(P<0.001$ for both 1 day and 2 day-culture) (Fig. 5). It should be noticed that intensity of IL-8 secretion was significantly increased after 2 days compared to 1 day treatment $(P<0.001)$.

The presence of $\mathrm{NaB}$ in Caco-2 cell cultures increased the percentage of floating cells. The increase in the number of cells that became detached from the tissue culture flasks was proportional to the butyrate concentration 

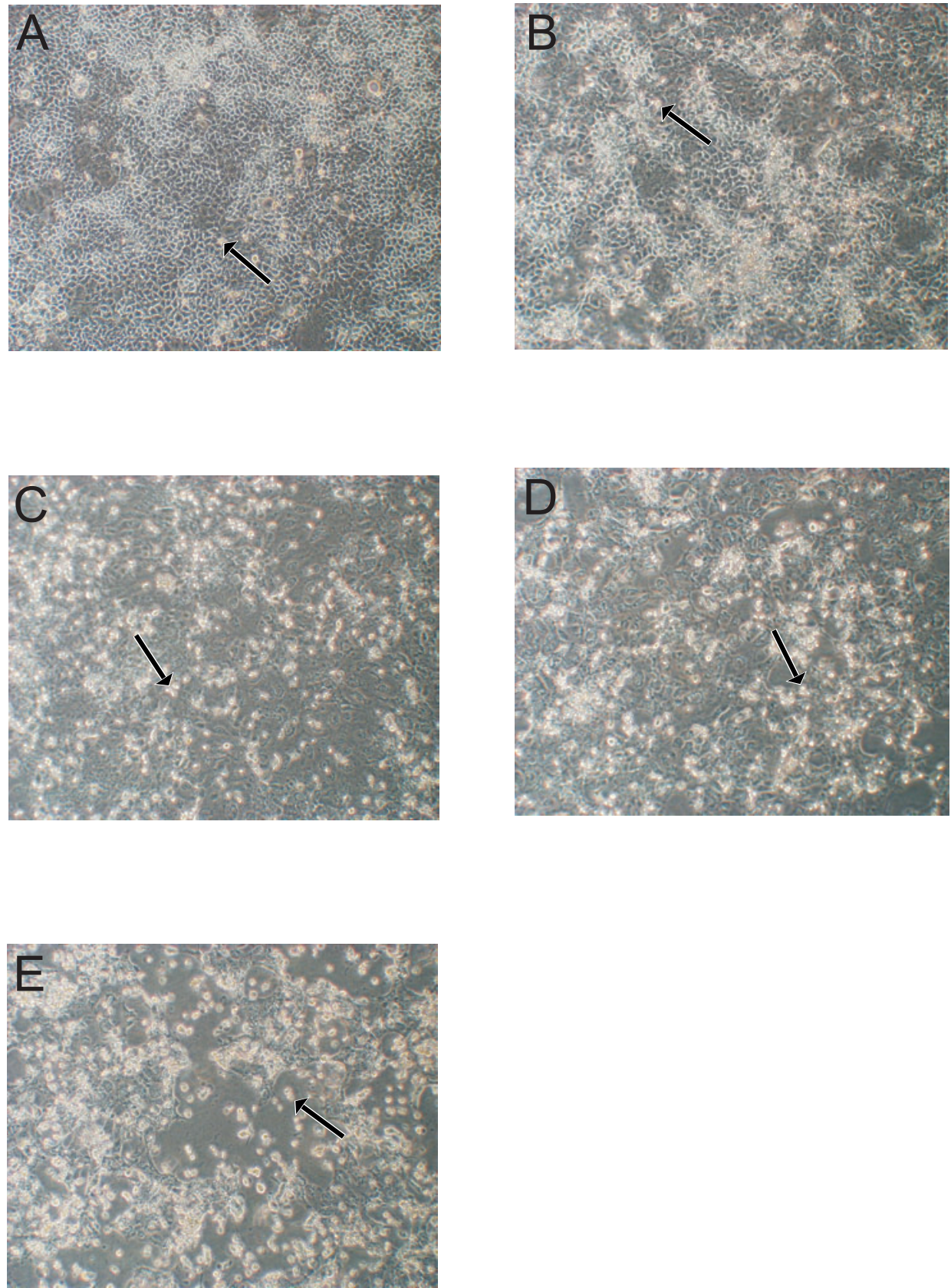

Figure 3. Five day Caco-2 cell cultures, treated with various concentrations of NaB.

A, control culture; B, C, D, E, cultures treated with $2.5 \mathrm{mM} ; 5 \mathrm{mM} ; 10 \mathrm{mM} ; 20 \mathrm{mM} \mathrm{NaB}$, respectively. Arrows indicate cells floating in the culture medium; (magnification $\times 100$ ).

(Fig. 6). Examination of these floating cells by acridine orange (Fig. 7) and Hoechst 33342 staining showed that the floating cells population consisted largely of apoptotic cells with the classical condensed chromatin. In the control cell cultures (not treated with $\mathrm{NaB}$ ) the number of floating cells was low (1-3\%) (Fig. 3). They displayed apoptotic cell morphology indicating that they resulted from spontaneous cellular death.
Examination of the adherent fraction after treatment with $\mathrm{NaB}$ showed that the proportion of apoptotic cells in the attached compartment was low compared with the floating cell fraction, that is below 10\% compared with around $50-60 \%$ apoptotic floating cells after 2 days of treatment with $\mathrm{NaB}$, and about $20 \%$ compared with $70-90 \%$ apoptosis in floating cells after 5 days of treatment with $\mathrm{NaB}$. The proportion of apoptotic cells in the control ad- 

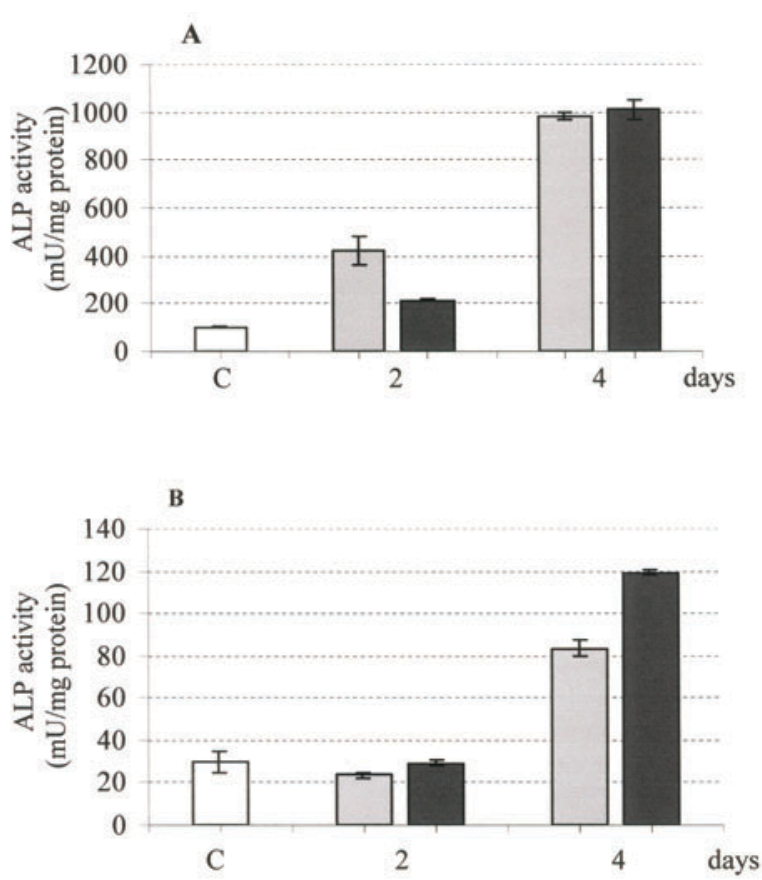

Figure 4. Effect of $5 \mathrm{mM}(\square)$ and $10 \mathrm{mM}(\square)$ butyrate on ALP activity in attached (A) and floating (B) Caco-2 cells, after 2 days and 4 days of culture.

Control cells ( $\square$ ) were cultured for 4 days without $\mathrm{NaB}$. After lysis of cells, enzyme activity was assessed by synthetic substrate digestion and colorimetric quantitation of the reaction product. Each bar represents the mean \pm S.D. of three independent experiments.

herent cell population was insignificant, typically around $1-2 \%$ (Fig. 7).

Our experiments with culturing of Caco-2 cells on laminin versus plastic were designed to see whether the presence of the main com-

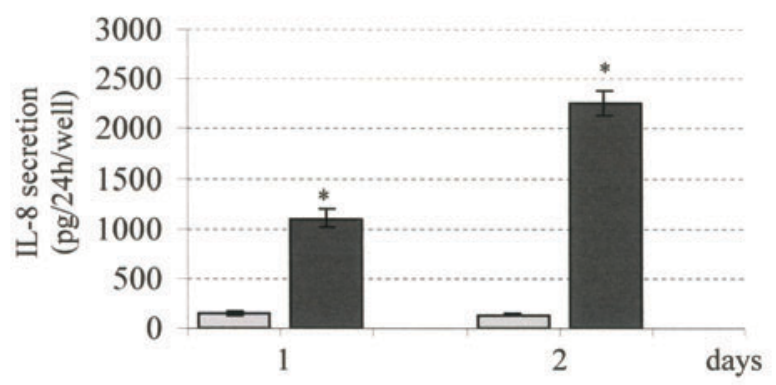

Figure 5. Time dependent stimulation of interleukin-8 (IL-8) secretion in Caco-2 cell line by 5 mM NaB ( $\square$ ) compared to control cells ( $\square$ ).

IL-8 content in culture supernatants was determined by ELISA. Each bar represents the mean \pm S.D. of three independent experiments; ${ }^{*} P<0.001$.
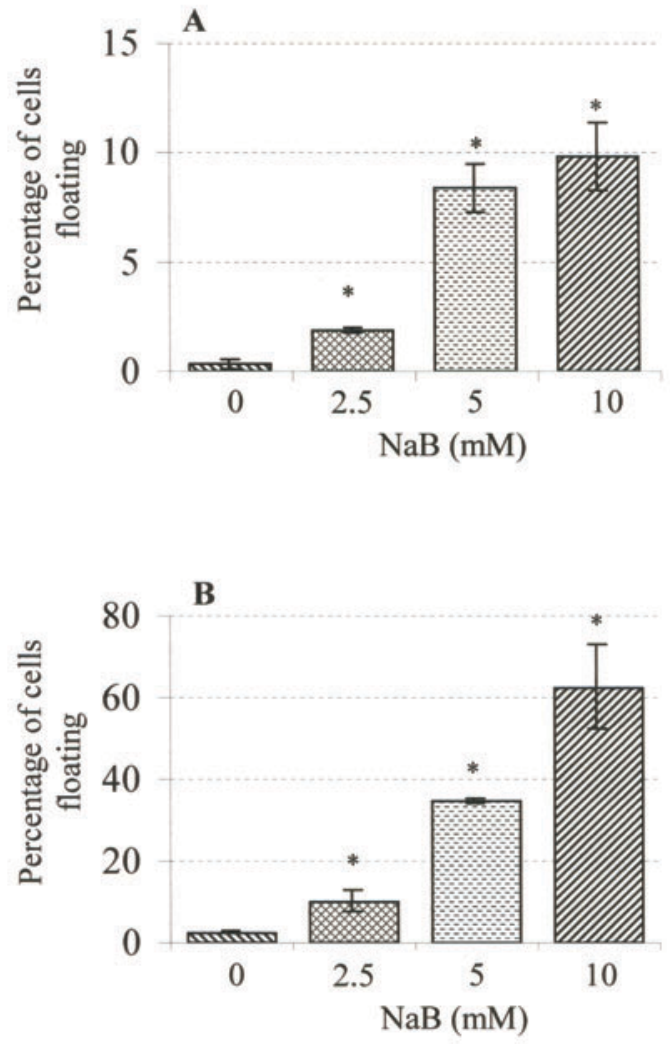

Figure 6. Effect of $\mathrm{NaB}$ treatment on the percentage of floating Caco-2 cells measured after 2 days (A) and 5 days (B) of incubation.

Cells were cultured on standard plastic dishes for 3 days and then treated with $\mathrm{NaB}$. Cells floating in the culture medium and cells attached to the tissue culture flask were counted separately using a hematocytometer. Each bar represents the mean \pm S.D. of three independent experiments; ${ }^{*} P<0.05$.

ponent of basal laminae, facilitating strong adhesion of cells to matrix, could modulate the influence of butyrate on the attached and floating cell yield (Fig. 8). However, we did not see any significant differences in cellular behaviour between cells cultured on laminin and on plastic in the presence of $10 \mathrm{mM} \mathrm{NaB}$ in terms of adherent cell number and frequency of apoptosis. As evidenced by fluorescent dyes staining culturing of cells on laminin did not change the proportion of apoptotic cells either in the attached or floating cell population after $\mathrm{NaB}$ treatment, compared to culturing them on plastic.

In cells culturing on dishes coated with polyHEMA, shortly after culture start, both single cells and some clusters consisting of 

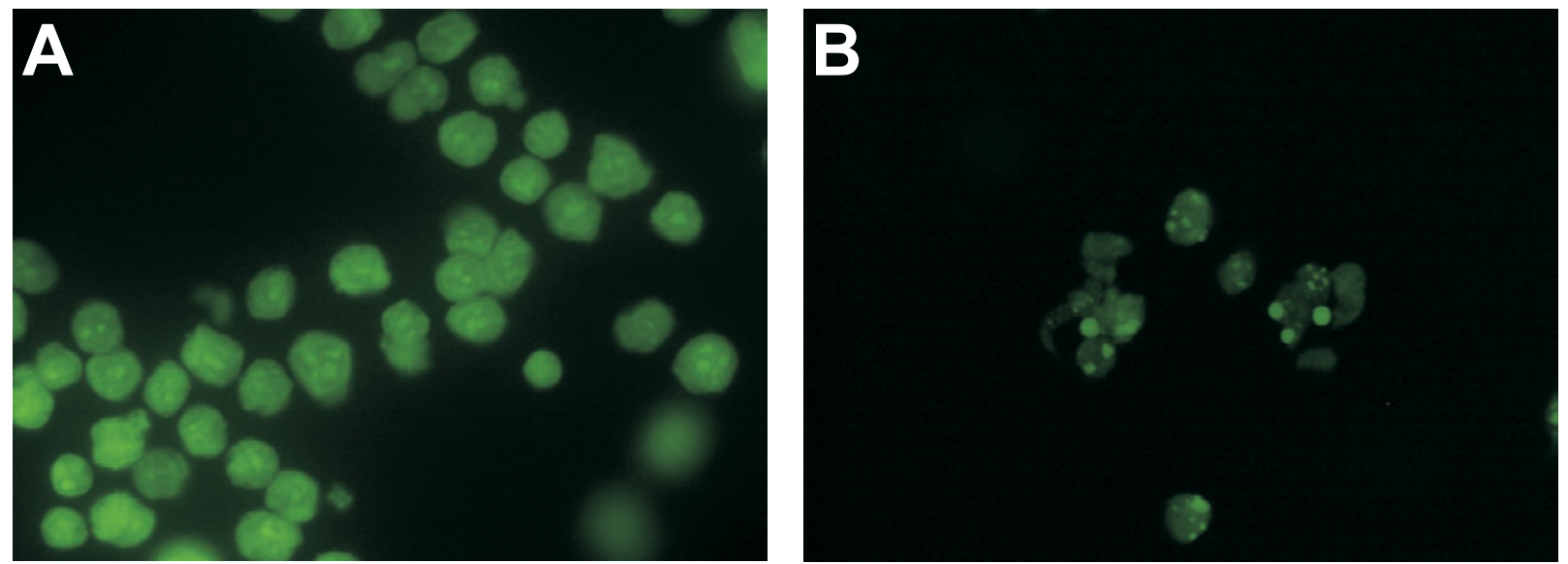

Figure 7. Caco-2 cells stained with acridine orange: adherent cells not treated with NaB (A), floating cells from $\mathrm{NaB}$ treated culture, displaying typical apoptotic morphology (B); (magnification $\times 400)$

several cells could be observed by microscopy. These cell clusters could not be disrupted by severalfold pipetting of the suspension. As early as after 1 day culture, the cells remaining in the floating cell fraction combined together to form multicellular organoids
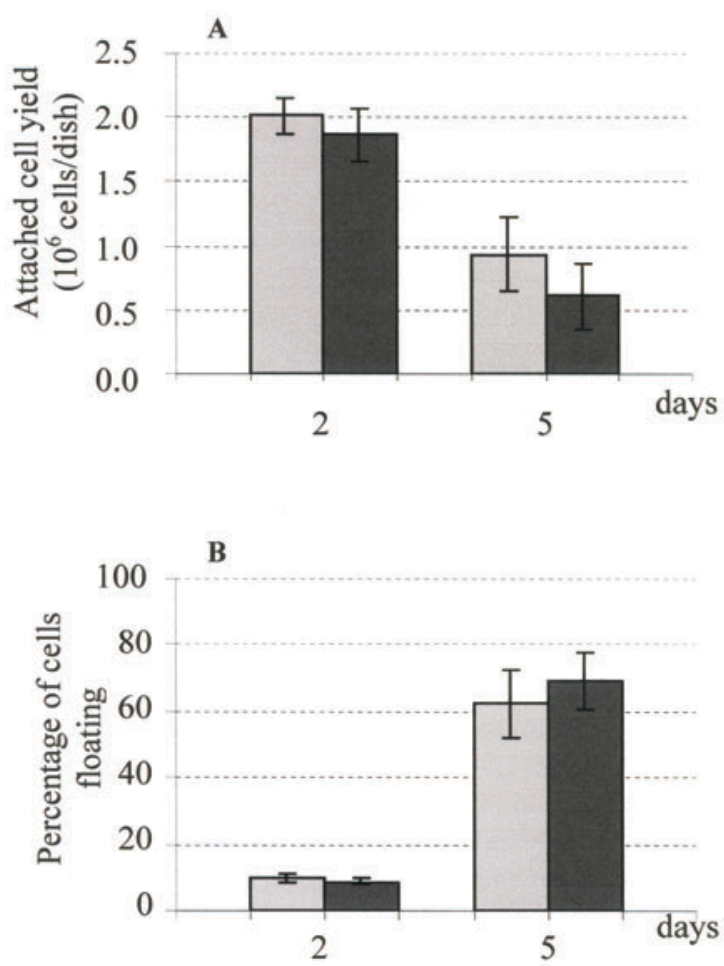

Figure 8. Effect of a 2-day and 5-day treatment with $10 \mathrm{mM} \mathrm{NaB}$ on the attached cells yield (A) and percentage of floating cells (B).

Cells were cultured on standard plastic substrate $(\square)$ and on laminin substrate $(\square$ ) for 3 days and then treated with $\mathrm{NaB}$. Floating cells and attached cells were counted separately using a hematocytometer. Each bar represents the mean \pm S.D. of 3 experiments. $P>0.05$.
(Fig. 9). These structures were increasing in size on successive days (up to 4 days) of culture. Staining with trypan blue showed that cells within these structures were alive with intact cell membrane. Examination by Hoechst 33342 staining demonstrated that organoids were composed of cells that were scored as non-apoptotic. The experiment with plating Caco-2 cells on polyHEMA coated dishes was performed to confirm the role of $\mathrm{NaB}$, in the presence of which the cells that became released from matrix were apoptotic. In the absence of $\mathrm{NaB}$ the cells, even when unable to adhere, retained intercellular junctions and escaped apoptosis.

\section{DISCUSSION}

The effect of butyrate on the epithelial cells of colon both in vivo and in vitro, depends on their phenotype (normal or transformed). Its effect on the turnover, structure and function of cells have been studied in vitro, particularly in colon cancer cell lines [2]. In normal colonic epithelial cells, it has proved difficult to show many of the effects observed in cell lines. The trials at culturing the normal colonic cells have been undertaken for a long time, however, in most cases, the cells retained viability and proliferation capability only for 3-5 days, and then they were gradually dying [18]. 

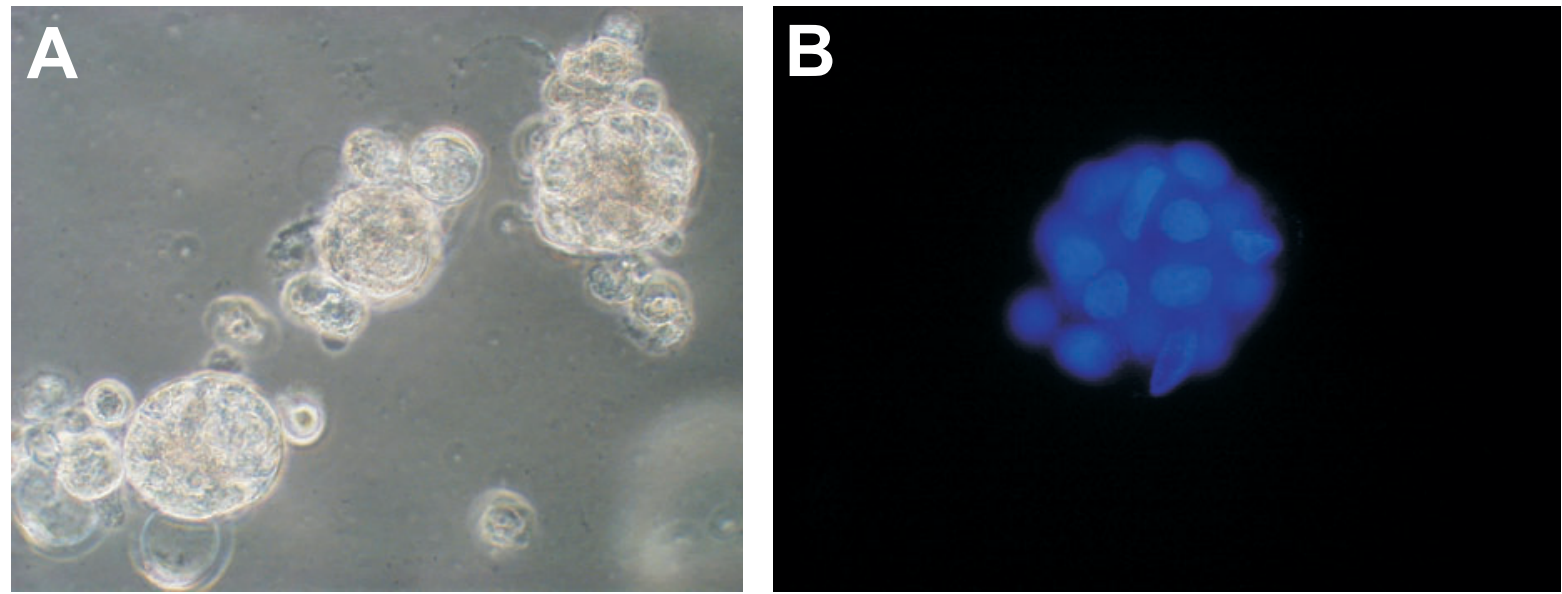

Figure 9. Spherical organoids composed of living Caco-2 cells cultured in suspension (magnification $\times 100$ ) (A); Organoids composed of Caco-2 cells stained with Hoechst 33342, displaying a morphology typical for normal (not apoptotic) cells (magnification $\times 400)(B)$.

The Caco-2 cell line is a well established model of human colorectal tumour and it represents a selected population of colon cancer cells that have adapted to conditions in vitro.

In the present study an analysis of the effect of butyrate on Caco- 2 cells revealed the inhibition of cell proliferation, induction of ALP and stimulation of apoptosis. The concentrations of $\mathrm{NaB}$ applied in our studies were consistent with its levels in the human colonic lumen [19].

The inhibition of cell proliferation was observed both in cultures into which $\mathrm{NaB}$ was added in the logarithmic phase of cell growth, and in cultures in which $\mathrm{NaB}$ was present at the time of plating.

Butyrate, which has been documented to be a differentiating agent $[2,9-11,20]$, was able to enhance ALP activity in Caco-2 cells. The ALP activity was measured in both adherent and floating cell populations to see whether the cells undergoing apoptosis were differentiated. We found that floating cells, which were mostly apoptotic, exhibited lower ALP activity compared with adherent cells. This might reflect the in vivo action of $\mathrm{NaB}$, which could induce apoptosis also in the cells not terminally differentiated and, thus, having a greater ability to proliferate and form metastase. The relationship between enterocyte-like differentiation and apoptosis was the subject of studies performed by Litvak et al.
[20] who showed that programmed cell death is associated with differentiation in Caco-2 cells, and suggested that apoptosis is a necessary component of terminal enterocyte differentiation. According to Mariadason et al. [21], $\mathrm{NaB}$ maximally induced apoptosis in undifferentiated Caco-2 cells, but this effect was significantly diminished when progressively more differentiated cells were exposed to butyrate.

Thus, one possible role of $\mathrm{NaB}$ in vivo is that it acts as an inducer of apoptosis in neoplastic or damaged cells, thus reducing the risk of cancer. The regulation of apoptosis in the colon is important since even low levels of apoptosis, if not balanced by proliferation have been shown to result with time in significant tissue regression [17]. Hence, small changes in butyrate-induced growth or apoptosis may favour a transition of cells from a normal to a transformed state.

The potential importance of considering the response of cells to $\mathrm{NaB}$ which was added to the cells at the moment of their seeding may be also relevant to $\mathrm{NaB}$ protective role against colorectal cancer. $\mathrm{NaB}$ diminished adhesion of cells suspended in the medium to plastic and stimulated their apoptosis, which was reflected by significantly enhanced floating cell yield and high percentage of cells with apoptotic morphology in this population. Butyrate-induced reduction of adhesion of Caco-2 cells might reflect altered cell-matrix interac- 
tions. NaB might have also affected junctional complexes which, in turn, affected the intercellular adhesive capacity, as cells in the floating cell compartment remained as separate ones. Our observation may have implications for the situation in vivo, where $\mathrm{NaB}$ may inhibit spreading and adhesion of free epithelial cancer cells which have lost adhesiveness to the matrix, by promoting their apoptosis.

In the absence of $\mathrm{NaB}$, however, cells which were forced to remain in the suspension in polyHEMA coated dishes, did not undergo apoptosis and joined together retaining intercellular junctions.

Treatment of Caco-2 cells with NaB markedly stimulated IL-8 secretion. There is evidence that the intestinal epithelium is able to secrete a wide variety of cytokines, including chemokines, which alter responses of the mucosal immune system [19, 22]. It is known that invasive bacteria may induce the release of IL-8 [23], and we wanted to check whether epithelial cells responded to $\mathrm{NaB}$, the normal constituent of the intestine, in terms of IL- 8 secretion. Our present data demonstrate that a normal metabolic product of intestinal bacteria, $\mathrm{NaB}$, increased the secretion of IL- 8 by Caco-2 cells. From this observation we can conclude that $\mathrm{NaB}$ not only functions as an energy source, but it can modulate the intestinal epithelial cell's response to inflammatory mediators, resulting in chemokine secretion.

Our studies showed that transformed Caco-2 cells did not retain their malignant phenotype. They appeared to undergo a change in the phenotype, induced by $\mathrm{NaB}$, as indicated by reduced proliferation, enhanced differentiation, stimulation of apoptosis leading to decreased viability of cells and stimulation of IL-8 secretion. Considering all the above facts and data, one could consider the Caco- 2 cells cultured in $\mathrm{NaB}$ supplemented medium as a model of non-malignant cells. We hypothesize that their phenotype closely resembles that of the cell from which the Caco-2 line has been derived.
We thank Ms. Lidia Świątkowska for her help in statistical analysis.

\section{R E F E R E N C E S}

1. Wolin, M.J. (1994) Control of short chain volatile acid production in the colon; in Short-chain Fatty Acids (Cummings, J., Binder, H.J. \& Soergel, K., eds.) pp. 3-10, Kluwer Academic Publishers, Boston.

2. Dzierżewicz, Z., Kwapisz, I., Cwalina, B. \& Wilczok, T. (1999) The role of butyric acid in growth, proliferation and differentiation of colonocytes. Gastroenterol. Pol. 6, 153-159.

3. Gibson, P.R., Moeller, J., Kagelari, O., Folino, M. \& Young, G.P. (1991) Contrasting effects of butyrate on expression of phenotypic markers of differentiation in neoplastic and non-neoplastic colonic epithelial cells in vitro. $J$. Gastrol. Hepatol. 7, 165-172.

4. Young, G.P. \& Gibson, P.R. (1994) Butyrate and the colorectal cancer cell; in Short-chain Fatty Acids (Cummings, J., Binder, H.J. \& Soergel, K., eds.) pp. 148-160, Kluwer Academic Publishers, Boston.

5. Gibson, P.R., Rosella, O., Wilson, A.J., Mariadason, J.M., Rickard, K., Byron, K. \& Barkla, D.H. (1999) Colonic epithelial cell activation and the paradoxical effects of butyrate. Carcinogenesis 20, 539-544.

6. Scheppach, W.M., Bartram, P., Richter, A., Richter, F., Liepold, H., Dusel, G., Hofstetter, G., Ruthlein, J. \& Kasper, H. (1992) Effect of short-chain fatty acids on the human colonic mucosa in vitro. J. Parenter. Enteral. Nutr. 16, $43-48$.

7. Kripke, S.A., Fox, A.D., Berman, J.M., Settle, R.G. \& Rombeau, J.L. (1989) Stimulation of intestinal mucosal growth with intracolonic infusion of short-chain fatty acids. J. Parenter. Enteral. Nutr. 13, 109-116. 
8. Luciano, L., Hass, R., Busche, R., von Engelhardt, W. \& Reale, E. (1996) Withdrawal of butyrate from the colonic mucosa triggers "mass apoptosis" primarily in the $\mathrm{G}_{0} / \mathrm{G}_{1}$ phase of the cell cycle. Cell Tissue Res. 286, 81-92.

9. Basson, M.D., Turowski, G.A., Rashid, Z., Hong, F. \& Madri, J.A. (1996) Regulation of human colonic cell line proliferation and phenotype by sodium butyrate. Dig. Dis. Sci. 41, 1986-1993.

10. Gamet, L., Daviaud, D., Denis-Pouxviel, C., Remesy, C. \& Murat, J.C. (1992) Effects of short-chain fatty acids on growth and differentiation of the human colon-cancer cell line HT29. Int. J. Cancer 52, 286-289.

11. Heerdt, B.G., Houston, M.A. \& Augenlicht, L.H. (1994) Potentiation by specific shortchain fatty acids of differentiation and apoptosis in human colonic carcinoma cell lines. Cancer Res. 54, 3288-3293.

12. McIntyre, A., Young, G.P., Taranto, T., Gibson, P.R. \& Ward, P. (1993) Fermentation products of dietary fiber and protection against large bowel cancer in a rat model. Gut 34, 386-391.

13. D'Argerio, G., Cosenza, V., Delle Cave, M., Iovino, P., DellaValle, N., Lombardi, G. \& Mazzacca, G. (1996) Butyrate enemas in experimental colitis and protection against large bowel cancer in a rat model. Gastroenterology 110, 1727-1734.

14. Medina, V., Afonso, J.T., Alverez-Arguelles, H., Hernandez, C. \& Gonzales, F. (1998) Sodium butyrate inhibits carcinoma development in a 1,2-dimethylhydrazine-induced rat colon cancer. J. Ent. Parent. Nutr. 22, 14-17.

15. Scheppach, W.M., Sommer, H., Kirchner, T., Paganelli, G.M., Bartram, P., Christl, S., Richter, F., Dusel, G. \& Kasper, H. (1992) Effect of butyrate enemas on the colonic mucosa in distal ulcerative colitis. Gastroenterology 103, $51-56$.
16. Hague, A., Manning, A.M., Hanlon, K.A., Huschtscha, L.I., Hart, D. \& Paraskeva, C. (1993) Sodium butyrate induces apoptosis in human colonic tumour cell lines in a p53-independent pathway - implications for the possible role of dietary fibre in the prevention of large bowel cancer. Int. J. Cancer 55, 498-505.

17. Singh, B., Halestrap, A.P. \& Paraskeva, C. (1997) Butyrate can act as a stimulator of growth or inducer of apoptosis in human colonic epithelial cell lines depending on the presence of alternative energy sources. Carcinogenesis 18, 1265-1270.

18. Dzierżewicz, Z., Orchel, A., Świerczek-Zięba, G., Latocha, M., Cwalina, B. \& Wilczok, T. (2001) Cultivation of normal colonic epithelial cells. Gastroenterol. Pol. 8, 59-65.

19. Fusunyan, R.D., Quinn, J.J., Ohno, Y., McDermott, R.P. \& Sanderson, I.R. (1998) Butyrate enhances interleukin (IL)-8 secretion by intestinal epithelial cells in response to IL-1 $\beta$ and lipopolysaccharide. Pediatr. Res. 43, 84-90.

20.Litvak, D.A., Evers, M.B., Hwang, K.O., Hellmich, M.R., Ko, T.C. \& Townsend, C.M. (1998) Butyrate-induced differentiation of Caco-2 cells is associated with apoptosis and early induction of $\mathrm{p} 21^{\mathrm{Waf} 1 / \mathrm{Cip} 1}$ and $\mathrm{p} 27^{\mathrm{Kip} 1}$. Surgery 124, 161-170.

21. Mariadason, J.M., Velcich, A., Wilson, A.J., Augenlicht, L.H. \& Gibson, P.R. (2001) Resistance to butyrate-induced cell differentiation and apoptosis during spontaneous Caco-2 cell differentiation. Gastroenterology 120, 889899.

22. Stadnyk, A.W. (1994) Cytokine production by epithelial cells. FASEB J. 8, 1041-1047.

23. Eckmann, L., Kagnoff, M.F. \& Fierer, J. (1993) Epithelial cells secrete the chemokine interleukin-8 in response to bacterial entry. Infect. Immun. 61, 4569-4574. 